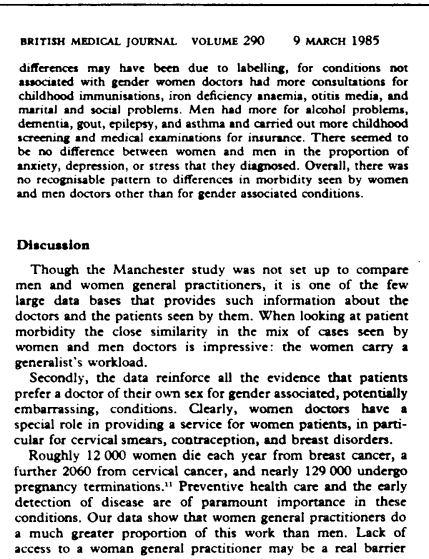

735 to preventive healch care for some women; in Manchester only
$333^{\circ}$ of of the practices offered patitits the option to con-

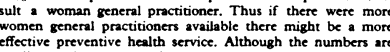

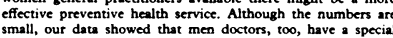

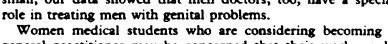

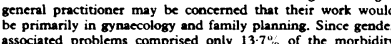

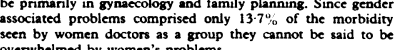

References

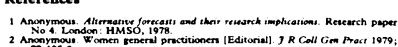

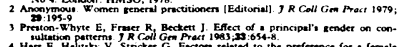

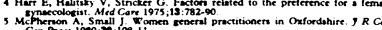

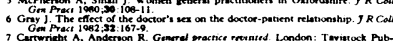

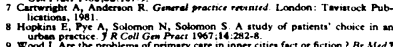

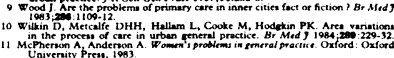
(1)

\title{
Women doctors in urban general practice: the doctors
}

$M$ COOKE, C RONALDS

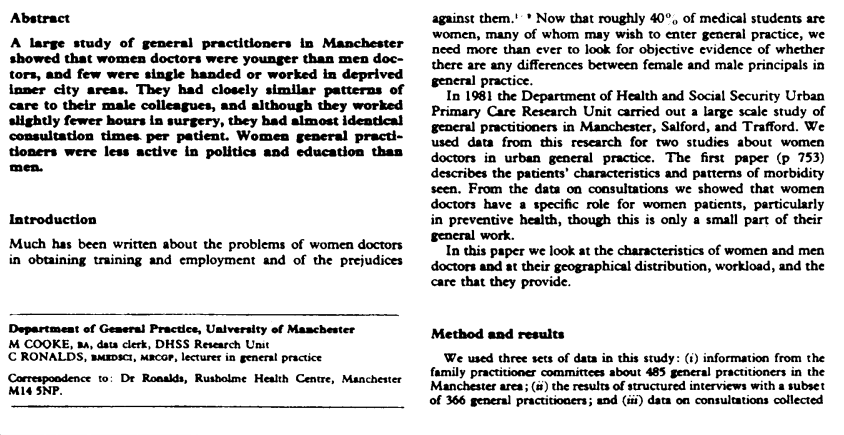


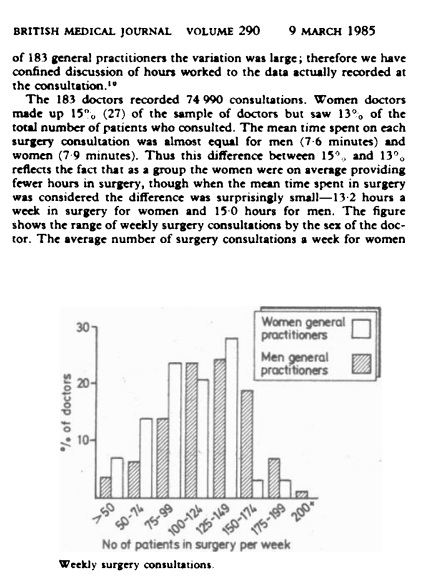

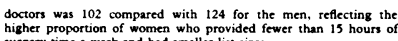

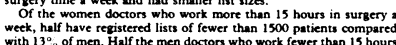

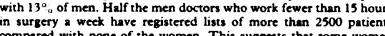

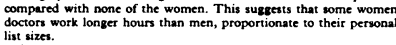

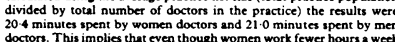

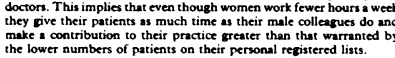

mocass of cane

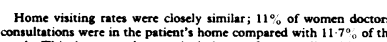

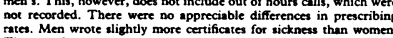

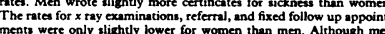

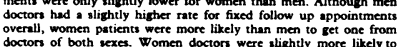

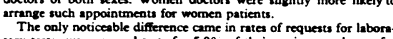

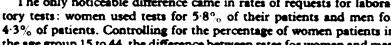

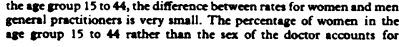

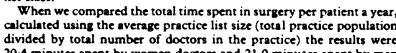

एᄆ

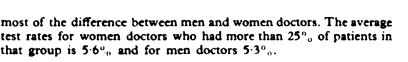
Discustion

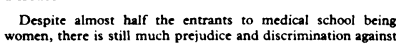

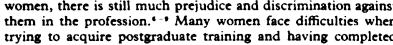

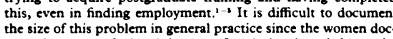

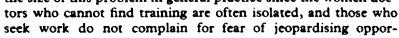

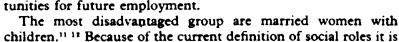

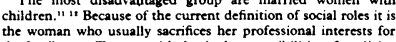

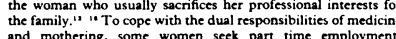

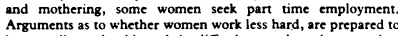
be on call, or should work in dificult areas have beca used

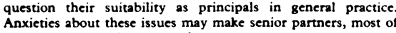

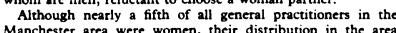

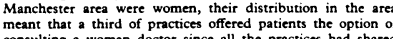

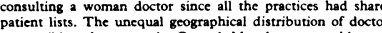

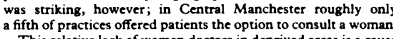

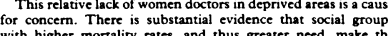

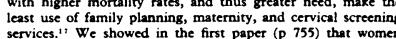

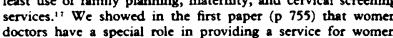

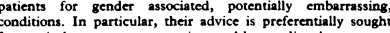

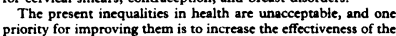

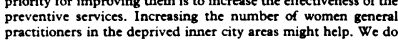

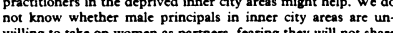

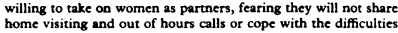

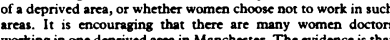

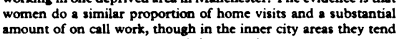

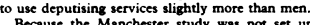

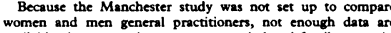

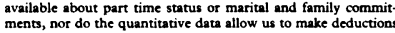

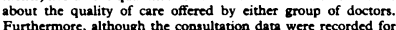

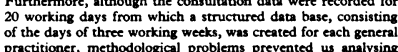

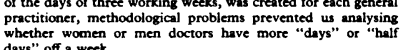
deys" of a week.
she data show, however, that women and men have closely
similar patterns of work and provide similar parterers of gare. similar patterns of worerk and provide similar parterns of acre.
Strikingly, there was no difference in the average duration of Strnkingly, there was no difference in the average duration of
consulations. Many women docrors undertake s full time work
commitiment, and although we cannot compare doctors commitment, and although we cannot compare doctors of
nominally full time or part time starus, the data are incriguing
758

The evergen number of hours a weck spent in surgery by all
women doctors is only 1.8 bours less than that for all mern

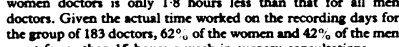

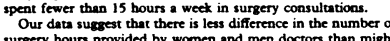

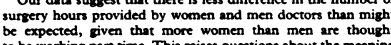

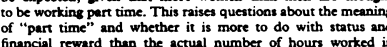
finencial reward than the actual number of hours worked in
consulutarions. Do women general prectitioners wort a similas

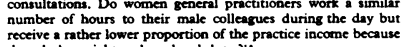

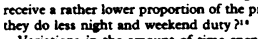

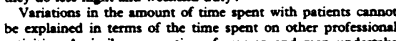

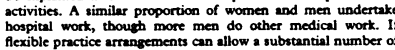

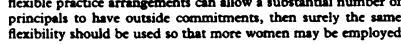

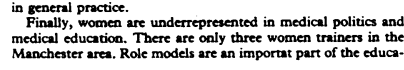

100 YEARS AGO

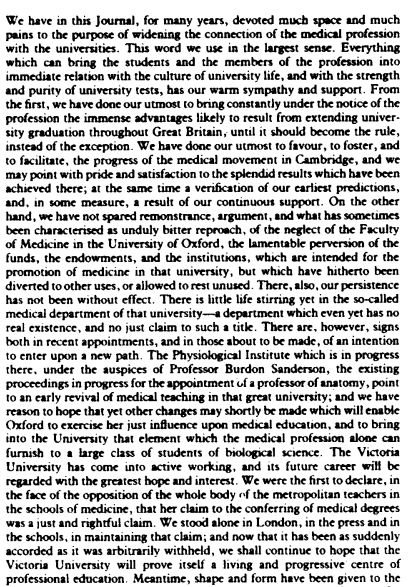

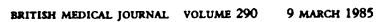
tional process, and barriers to the participation of women in
trainings and politica are to be deplored.

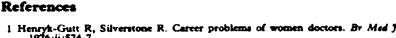

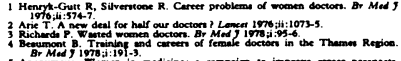

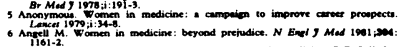

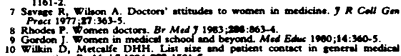

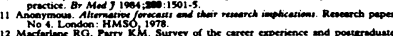

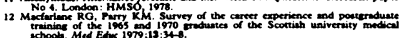

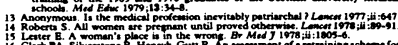

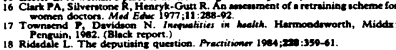

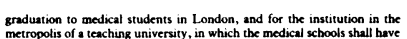

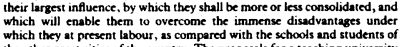

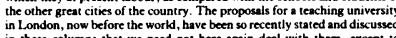

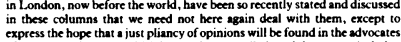

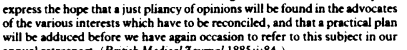

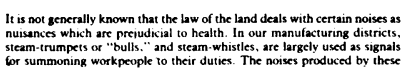

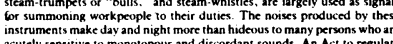

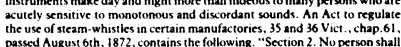

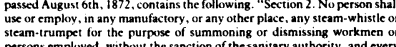

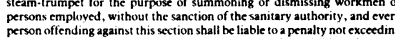

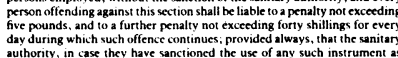

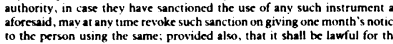

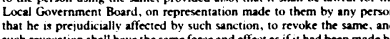

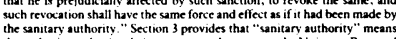

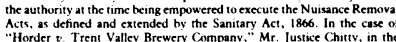

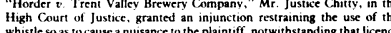

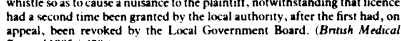

